\title{
Mapeamento da Pesquisa no Campo da Experimentação no Ensino de Química no Brasil
}

\section{Map of Research on Experimentation in Chemistry Teaching in Brazil \\ Renata Faria de Souza ; Patrícia Fernanda de Oliveira Cabral ${ }^{\text {; }}$; Salete Linhares Queiroz $^{\mathbf{a}}$}

a Instituto de Química de São Carlos, Universidade de São Paulo, São Carlos, Brasil - re-nataf@hotmail.com, salete@iqsc.usp.br

b Universidade de São Paulo, São Paulo, Brasil - petycabral@gmail.com

\section{Palavras-chave: \\ Experimentação. \\ Química. Estado da arte.}

Resumo: Este trabalho analisa a produção acadêmica expressa em dissertações e teses sobre a experimentação no ensino de química, defendidas em Programas de Pós-Graduação vinculados às áreas de Ensino, Educação e Química da CAPES, no período de 2004 a 2013. Foram investigadas 122 dissertações e 21 teses com base nos seguintes descritores: ano de defesa; grau de titulação acadêmica; região geográfica; instituição de origem; nível de escolaridade e foco temático. Os resultados evidenciam o significativo crescimento no número de pesquisas sobre o tema em questão. Os níveis de escolaridade mais investigados foram o ensino médio $(68,5 \%)$ e superior $(27,3 \%)$, ao passo que os focos temáticos privilegiados foram experimentação como estratégia didática $(58,3 \%)$ e experimentação em materiais didáticos $(20,2 \%)$. A experimentação vinculada à formação inicial e continuada de professores foi abordada de forma incipiente, $7,1 \%$ e $13,1 \%$ da produção, respectivamente, indicando que essa é uma importante lacuna a ser preenchida por estudos futuros.

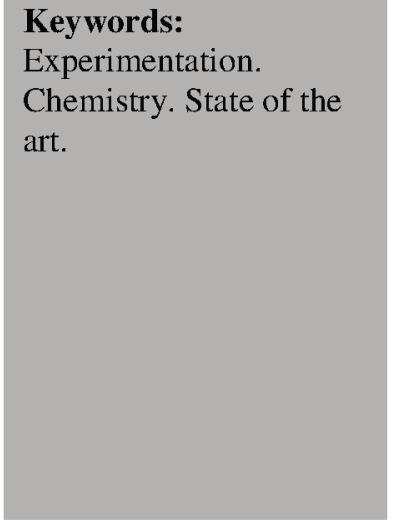

Keywords:

Chemistry. State of the art.

Abstract: This work analyzes the academic production expressed in dissertations and thesis on experimentation in Chemistry teaching, defended in Postgraduate Programs related to the areas of Teaching, Education and Chemistry of the CAPES from 2004 to 2013. Dissertations (122) and theses (21) were investigated based on the following descriptors: year of defense; level of academic qualification; geographical region; institution; educational level and thematic focus. The results showed a significant growth in the number of studies on the subject in question. The most researched levels of education were high school (68.5\%) and higher education $(27.3 \%)$, whereas the most important thematic focus was experimentation as a didactic strategy $(58.3 \%)$ and experimentation in teaching materials $(20.2 \%)$. Experimentation related to preservice and inservice teacher education was still incipient, $7.1 \%$ and $13.1 \%$ of production, respectively, enabling us to infer that this is an important gap to be filled by future studies. 


\section{Introdução}

Estudos sobre o estado da arte buscam mapear determinada produção acadêmica, tendo em vista a discussão a seu respeito, assim como a indicação sobre os aspectos por ela destacados ou negligenciados (FERREIRA, 2002). Dentre as fontes empregadas em tais estudos estão dissertações de mestrado e teses de doutorado, assim como resumos e anais de congressos.

Segundo Teixeira e Megid Neto (2006), em pesquisas do tipo estado da arte os autores trilham um percurso que envolve duas dimensões: na primeira ocorre a análise inicial do conjunto de trabalhos, com a aquisição de um panorama geral da produção (evolução quantitativa ao longo do tempo, instituições e regiões geográficas de realização, nível de ensino) e na segunda ocorre análise mais aprofundada sobre a produção, na busca por identificação de tendências e focos temáticos, além da própria abordagem teóricometodológica existente nos trabalhos.

Nessa perspectiva, analisamos dissertações de mestrado e teses de doutorado defendidas no país sobre experimentação no ensino de química junto aos Programas de PósGraduação (PPG) vinculados às áreas de Ensino (área 46), Educação (área 38) e Química (área 4) da Coordenação de Aperfeiçoamento de Pessoal de Nível Superior (CAPES), no período de 2004 a 2013. Concordamos com Megid Neto (1999), quando o autor afirma que grande parte das investigações realizadas nas Instituições de Ensino Superior (IES) está vinculada aos cursos de mestrado e doutorado, o que justifica a nossa escolha pelo conjunto de documentos citado.

Trabalhos nos quais autores brasileiros compartilham do nosso propósito de conhecer com maior profundidade as pesquisas realizadas sobre experimentação no ensino de química são reportados na literatura, dentre os quais destacamos a dissertação de mestrado e tese de doutorado de Gonçalves $(2005,2009)$. Como desdobramento da dissertação, intitulada "O texto de experimentação na educação em química: discursos pedagógicos e epistemológicos" (Gonçalves, 2005), foi publicado o artigo "Contribuições pedagógicas e epistemológicas em textos de experimentação no ensino de química" (GONÇALVES; MARQUES, 2006). Nessa pesquisa os autores estudaram as características dos discursos sobre propostas de experimentos divulgados na seção Experimentação no Ensino de Química, da revista Química Nova na Escola (QNEsc). Para compreender as características dos discursos sobre as atividades experimentais foram analisados 38 artigos da seção publicados entre 1995 e 2003. A partir de uma abordagem pedagógica e epistemológica, a análise dos dados teve como meta problematizar a experimentação na formação docente e repensar as características metodológicas das atividades experimentais no ensino de química. 
A partir da tese do referido autor, intitulada "A problematização das atividades experimentais no desenvolvimento profissional e na docência dos formadores de professores de química" (Gonçalves, 2009), foram publicados dois artigos. No primeiro, "A problematização das atividades experimentais na educação superior em química: uma pesquisa com produções textuais docentes" (GONÇALVES; MARQUES, 2011), foram selecionados 102 artigos, produzidos no período de 1980 a 2007, publicados na seção de Educação da revista Química Nova. A partir dessa seleção, foram investigados os discursos pedagógicos, epistemológicos e ambientais relativos à experimentação presentes entre professores de química da educação superior, como um modo de apontar características importantes a incorporar em experimentos. O objetivo da pesquisa foi contribuir com a apresentação de possibilidades metodológicas para a abordagem das atividades experimentais na educação superior em química.

Já o artigo publicado em 2012, intitulado “A problematização das atividades experimentais na educação superior em química: uma pesquisa com produções textuais docentes - parte II" (GONÇALVES; MARQUES, 2012a), é uma continuidade das investigações realizadas na publicação de 2011. Para esse artigo, o material de análise, o percurso metodológico e os objetivos são os mesmos que foram mencionados no estudo anterior. No entanto, nele os autores discutem novas categorias de análise.

No terceiro artigo, de autoria de Gonçalves e Marques (2012b), "A circulação inter e intracoletiva de pesquisas e publicações acerca da experimentação no ensino de química", foi traçado um panorama sobre a experimentação no ensino de química por meio da identificação de dissertações, teses e artigos publicados em periódicos nacionais acerca dessa temática. Foram identificados, no período entre 1972 e 2006, dezoito trabalhos realizados em PPG e quinze artigos em periódicos da área de ensino de química e ciências. A maior parte das dissertações e teses foi publicada entre 2001 e 2006, enquanto a publicação do maior número de artigos antecedeu esse período. As pesquisas em PPG foram realizadas principalmente em nível de mestrado e a articulação da temática em questão à educação superior e à formação docente foi caracterizada como incipiente. Por outro lado, a maior parte dos artigos publicados na revista Química Nova se dedicava ao ensino superior. Foi ainda observada a expansão de PPG em ensino de ciências como contribuintes do aumento do número de teses e dissertações em torno do assunto tratado no estudo.

Silva et al. (2009) também tomaram como objeto de estudo artigos publicados na seção Experimentação no Ensino de Química da QNEsc. Os autores publicaram os resultados da análise de 44 artigos publicados entre 2000 e 2008 com o intuito de investigar se e como a contextualização é neles contemplada. Os resultados apontam que certos temas, como alimentos e plástico, são mais explorados que outros nos artigos que apresentam algum tipo 
de contextualização. Os autores salientam que, embora a contextualização não se constitua em critério da revista para a publicação na referida seção, a concepção de contextualização que vem sendo proposta tem se aprimorado, ao longo das edições.

Em artigo mais recente, Ferreira e Amaral (2015) analisaram resumos disponíveis no Banco de Teses e Dissertações da CAPES de trabalhos sobre experimentação no ensino de química, no período de 2002 a 2011. Os autores classificaram os 40 trabalhos encontrados com o objetivo de tecer considerações acerca de como os pesquisadores desenvolvem este tipo de atividade. Após a leitura inicial, foram selecionados 23 trabalhos que tratavam da experimentação investigativa com resolução de problemas. A análise se sucedeu com a organização dos dados, leitura para delinear categorias e focos temáticos. A partir disso, os autores indicaram dois focos temáticos principais, sendo o primeiro deles o foco no professor e o segundo o foco no aluno. Foi encontrado um maior número de trabalhos com foco no aluno, centrados em sua aprendizagem (FERREIRA; AMARAL, 2015).

Trabalhos sobre a temática foram também apresentados nos Encontros Nacionais de Pesquisa em Educação em Ciências (ENPEC) (MATIELLO et al., 2011; SOUZA; BROIETTI, 2017), com destaque para o de autoria de Matiello et al. (2011), intitulado "Experimentação no ensino de química: uma análise das dissertações e teses da USP". Os autores realizaram a análise das referências bibliográficas utilizadas na produção de dissertações e teses desenvolvidas na Universidade de São Paulo (USP), entre os anos de 2000 e 2009, que tratam do tema em questão. Foram analisados dez documentos no referido período e, no total, foram apresentadas 722 referências bibliográficas, a maioria delas corresponde a artigos publicados em periódicos $(45,5 \%)$, seguidos de referências a livros $(37,4 \%)$. Os autores concluíram que o campo da pesquisa em ensino de química apresentou grande crescimento nas últimas décadas e que a USP contribuiu de forma significativa para o desenvolvimento da área, não apenas na região Sudeste, mas em todo o país. No entanto, a temática experimentação, embora apresente um crescente interesse, ainda é pouco investigada nos trabalhos oriundos dessa universidade.

Tendo em vista o exposto, é possível afirmar que são ainda poucos os estudos do tipo estado da arte que se dedicam a explorar a questão da experimentação no ensino de química. Dessa forma, as considerações decorrentes do presente trabalho podem contribuir para que as discussões sobre a temática evoluam e fortaleçam o oferecimento de um ensino de química alinhado com as tendências atuais e com a realização de atividades que se desvencilhem do perfil empírico-indutivista, que usualmente se apresenta como característico das atividades experimentais realizadas em ambientes de ensino desde o seu surgimento (SILVA et al., 2009). 
Nesse contexto, buscamos responder a seguinte questão norteadora: Quais são as principais características da pesquisa acadêmica brasileira sobre a experimentação no ensino de química no Brasil? Na busca de respostas para tais questionamentos, os seguintes aspectos foram considerados na análise dos documentos localizados: ano de defesa, grau de titulação acadêmica, região geográfica, instituição de origem, nível de ensino ao qual se referem e foco temático.

\section{Percurso metodológico}

A abordagem metodológica utilizada nesta pesquisa foi do tipo estado da arte (FERREIRA, 2002), levada a cabo em duas etapas. Na primeira, realizaram-se a pesquisa, identificação, aquisição e o agrupamento das dissertações de mestrado e teses de doutorado, referentes à experimentação no ensino de química, defendidas nos PPG pertencentes às áreas 46, 38 e 4 da CAPES, no período de 2004 a 2013. Cabe ressaltar que no ano de 2011 a área de Ensino de Ciências e Matemática foi extinta e criada a área de Ensino (CAPES, 2011). A busca das dissertações e teses foi encerrada em dezembro de 2015. Os documentos foram consultados a partir da listagem de sites dos PPG, disponibilizada no site da CAPES. Dentre os sites dos PPG, alguns apresentavam apenas uma listagem com as referências das dissertações e teses defendidas. Por outro lado, outros sites de PPG consultados disponibilizavam o acesso via download dos arquivos dos trabalhos completos.

Quando ocorreram situações nas quais somente a listagem era oferecida, existiu a necessidade de consulta on-line do acervo de dissertações e teses disponibilizadas pelas bibliotecas das instituições de origem dos trabalhos para verificação da existência ou não dos trabalhos buscados. Aqueles disponibilizados on-line foram obtidos de forma imediata e para os demais casos foi necessário contato com o autor (via e-mail), a quem foi solicitado o envio de uma cópia do mesmo. Em relação aos trabalhos da Universidade Federal de São Carlos e do Instituto de Química de São Carlos (USP) que não estavam disponíveis on-line, foi realizado o deslocamento até as instituições para a sua obtenção. Na segunda etapa foi feita a leitura, análise e classificação dos trabalhos de acordo com os descritores apresentados a seguir.

Nesta etapa da pesquisa foi definida uma metodologia de trabalho baseada na interação estabelecida entre pesquisador e objeto de estudo. Esta se pautou no exame e classificação dos textos por parte do pesquisador, a fim de reconhecer o objeto pesquisado. Assim, conforme mencionado anteriormente, duas etapas ocorreram durante a investigação: Primeira etapa

a) Identificação, obtenção e reunião das dissertações de mestrado e teses de doutorado, referentes à experimentação no ensino de química, defendidas nos PPG, pertencentes às áreas 
46, 38 e 4 da CAPES, no período de 2004 a 2013. Foram selecionados para análise documentos nos quais se encontrasse no título, no resumo, nas palavras-chave ou na ficha catalográfica referência à palavra "química", associada a "atividade experimental", "experimento", "experimentação", "aula prática" ou "laboratório".

\section{Segunda etapa}

a) Leitura e classificação das teses e dissertações de acordo com os descritores definidos na etapa anterior realizada de forma individual por duas das autoras deste trabalho;

b) Classificação e organização dos dados coletados em fichamentos para a geração de um banco de dados;

c) Reuniões regulares entre duas das autoras para a discussão dos dados obtidos a partir da classificação dos descritores, com a intenção de estabelecer um consenso sobre os resultados de cada descritor, a fim de validar os dados obtidos;

d) Organização dos resultados evidenciados em tabelas e gráficos considerando a classificação dos documentos com relação aos vários descritores analisados. Para essa etapa foi utilizado como ferramenta o programa Microsoft Office Excel® 2010;

e) Análise e discussão dos resultados a partir das principais particularidades constatadas nas dissertações e teses e das contribuições da produção acadêmica, com o objetivo de ressaltar os aspectos das pesquisas sobre experimentação no ensino de química, assim como as questões pouco ou ainda não investigadas sobre o tema em questão.

Nesse contexto, foram adotados os seguintes descritores:

- Ano de defesa: verificação do ano de defesa das dissertações e teses, com objetivo de analisar o desenvolvimento da produção acadêmica ao longo do tempo. Nesse sentido, foram observados e analisados os períodos de maior ou menor produção na área de pesquisa sobre a experimentação no ensino de química;

- Grau de titulação acadêmica: verificação dos trabalhos quanto ao grau de titulação, tendo como referência dissertações de mestrado ou tese de doutorado. Quanto às dissertações de mestrado, ainda foi realizado um desdobramento na classificação das mesmas em nível acadêmico ou profissional. Essa etapa visou o entendimento sobre o quanto e em qual profundidade o tema em foco tem sido abordado.

- Região geográfica e instituição de origem: verificação dos locais onde ocorreram as defesas dos trabalhos selecionados, considerando a região geográfica e a instituição de origem. Por meio dessa constatação, procurou-se compreender a base institucional que sustenta as pesquisas sobre experimentação no ensino de química;

- Nível de escolaridade: verificação a respeito do nível escolar/níveis escolares abordado(s) nos trabalhos selecionados. Segundo o trabalho de Francisco, Alexandrino e Queiroz (2015), os níveis identificados foram educação infantil, ensino fundamental, ensino 
médio, ensino superior e geral (trabalhos que apresentam discussões genéricas, sem abordagem específica para alguma etapa de escolarização). Com isso, foram obtidas informações sobre quais foram os níveis abordados, assim como sobre aqueles que foram alvo de pouca atenção por parte dos autores de cada área;

- Foco temático: verificação das temáticas abordadas nos documentos. Os focos temáticos foram analisados de acordo com a perspectiva da discussão sobre a experimentação. Se esta é privilegiada no trabalho, a classificação assumida foi "em destaque", caso contrário, a classificação assumida foi "no contexto". Ou seja, os trabalhos classificados "no contexto" foram aqueles nos quais a experimentação foi abordada de forma secundária, nesse caso a experimentação não foi objeto principal de pesquisa. Já os trabalhos classificados "em destaque" foram aqueles nos quais a experimentação era o foco principal da pesquisa, nesse caso as atividades experimentais se constituíam na principal metodologia utilizada nos trabalhos e/ou a experimentação era o tema principal da pesquisa. A partir da leitura dos trabalhos classificados "em destaque", emergiram as categorias de análise empregadas neste estudo, no que diz respeito ao foco temático. A saber:

Experimentação como estratégia didática: os trabalhos classificados neste foco estão relacionados à aplicação de atividades experimentais enquanto recurso didático em ambientes de ensino, com ou sem ênfase na construção de conhecimentos químicos.

Experimentação em materiais didáticos: os trabalhos classificados neste foco estão relacionados à elaboração, aplicação e análise de materiais didáticos nos quais atividades experimentais são discutidas.

Experimentação na formação inicial de professores: os trabalhos classificados neste foco investigam as percepções, concepções e representações dos licenciandos sobre elementos inerentes à experimentação, facilidades e/ou dificuldades enfrentadas no contexto educacional para a implementação.

Experimentação na formação continuada de professores: os trabalhos classificados neste foco estão relacionados a ações de formação continuada de professores que colocam em pauta a discussão e promovem reflexões sobre a experimentação no ensino de química e a investigação das percepções, concepções e representações dos professores sobre elementos inerentes à experimentação, facilidades e/ou dificuldades enfrentadas no contexto educacional para a implementação da mesma, assim como suas necessidades formativas frente à questão.

Experimentação em currículos e programas: trabalhos classificados neste foco discutem a forma como atividades experimentais são introduzidas e desenvolvidas nos vários níveis de ensino em disciplinas isoladas ou em um curso como um todo.

Outros: trabalhos classificados neste foco não são passíveis de classificação nos demais focos. 


\section{Resultados e discussão}

\section{A produção e sua distribuição no período analisado}

Considerando que não foi possível o acesso a três trabalhos, Santos (2012), Sithole (2004) e César (2008), ao todo foram reunidos 143 documentos, 122 dissertações e 21 teses, relacionados à experimentação no ensino de química, produzidos nos PPG das áreas 46, $38 \mathrm{e}$ 4, no período investigado. Quanto ao grau de titulação, foram localizados $85(59,4 \%)$ dissertações de mestrado acadêmico, $37(25,9 \%)$ dissertações do mestrado profissional e $21(14,7 \%)$ teses de doutorado.

Desse total, 69 dissertações e sete teses foram produzidas na área 46, dezessete dissertações e sete teses na área 38 e 36 dissertações e sete teses na área 4. Portanto, a área 46 foi a que mais contribuiu com a produção, seguida pela área 4 e pela área 38. A distribuição dos documentos de acordo com o ano de defesa relacionada às áreas 46, 38 e 4 está representada na Figura 1.

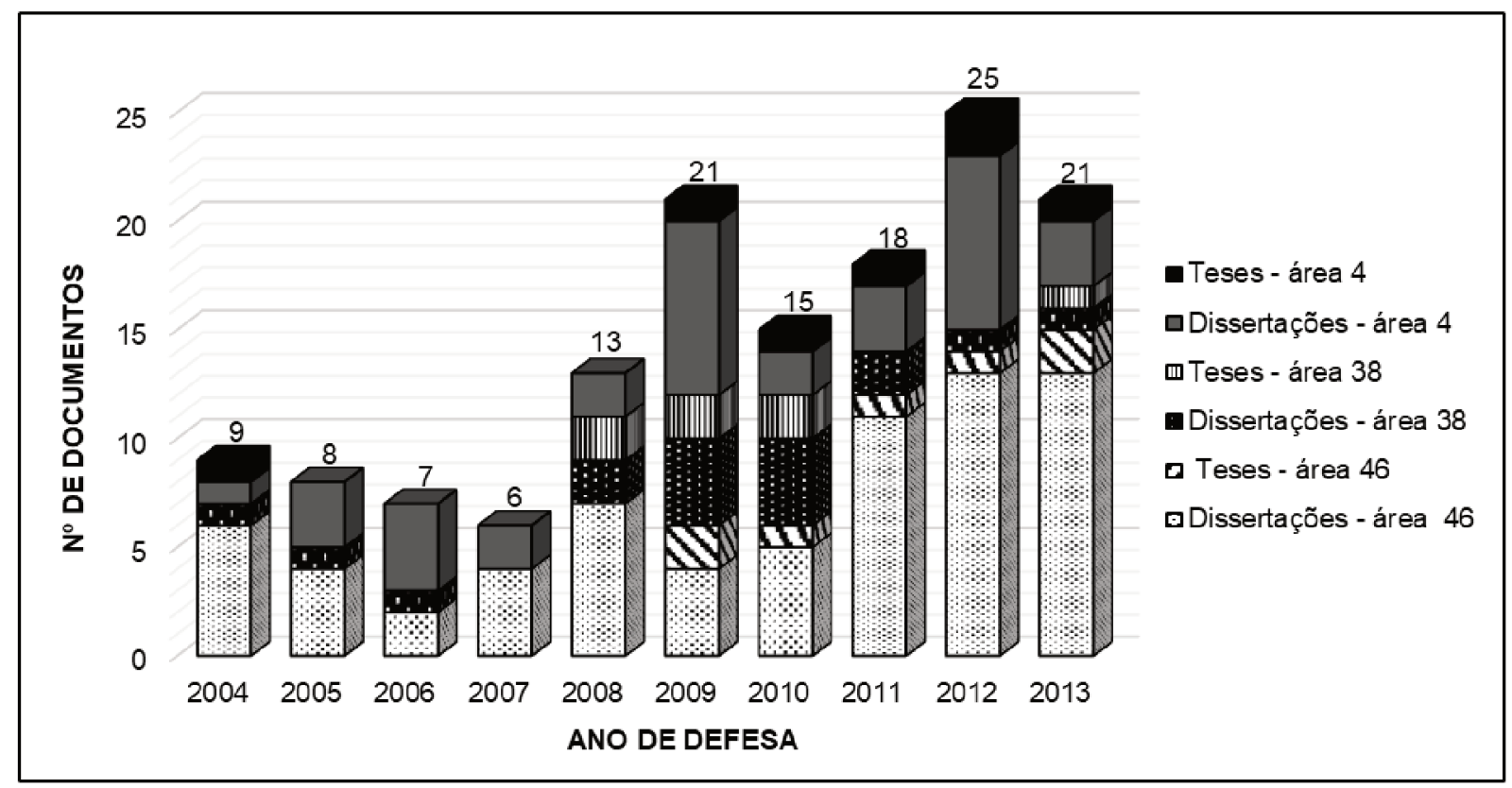

Figura 1 - Distribuição das dissertações e teses de acordo com o ano de defesa e área, no período de 2004 a 2013 Fonte: Elaboração dos autores

A Figura 1 ilustra a evolução da produção ao longo do tempo. Observa-se que a produção de trabalhos no período de 2004 a 2007 é mais ou menos constante, com uma média aproximada de sete trabalhos por ano. Embora de 2006 até 2007 a produção diminua, a partir de 2008 ocorre um aumento significativo, que em 2012 culmina com o maior número de produções: 22 dissertações e três teses. Ou seja, a produção quase triplicou de 2004 a 2012, o que sinaliza o crescente interesse de pesquisadores na investigação de assuntos relacionados à temática em foco.

Com relação à área 46, em 2004 foram finalizadas seis dissertações e a partir do ano seguinte houve uma queda na produção de trabalhos, de quatro para dois trabalhos em 2006. 
Entre 2007 e 2008 ocorreu um aumento significativo na produção de trabalhos, e de 2008 a 2010 se manteve constante, por volta de seis trabalhos por ano. Já entre 2011 e 2013 ocorreu um aumento na produção de trabalhos e em 2013 foi observado o maior número de produções: treze dissertações e duas teses. O aumento significativo da produção de trabalhos na área 46 no período de 2011 a 2013, comparativamente ao período de 2007 a 2010, pode ser atribuído ao reconhecimento de 26 novos PPG da área 46 pela CAPES entre 2007 e 2011. Considerando que as defesas de trabalhos ocorrem, usualmente, dois a três anos após o reconhecimento do PPG, o aumento da produção na área 46 se acentuou a partir de 2011. Fornece subsídio para o fortalecimento da hipótese acima aventada, o fato de nove, entre os quinze trabalhos defendidos em 2013, se originarem de PPG reconhecidos entre 2007 e 2011 , o que corresponde a $60,0 \%$ do total da produção desse ano. Nessa perspectiva, é possível inferir que a produção acadêmica brasileira em educação em química, referente especificamente à área 46, se desenvolveu na medida em que foram surgindo novos PPG, com a ampliação do número de vagas.

Quanto à área 38, observamos que a produção de trabalhos não variou muito, especialmente considerando determinados períodos. De 2004 a 2006 a produção se manteve constante, com um trabalho por ano. Entre 2008 e 2010 foi produzida uma média aproximada de cinco trabalhos por ano. Entre 2011 e 2013 o número de trabalhos diminuiu, com uma produção que variou de um a dois trabalhos por ano. No que se refere à área 4, esta apresentou 43 trabalhos. Fazendo um paralelo com os resultados obtidos por Silva e Queiroz (2016, 2017), os autores localizaram apenas doze trabalhos sobre o tema da formação de professores de química na área 4 , sugerindo ser o seu tema de investigação pouco difundido nesta área, em contraponto ao nosso, que trata da experimentação. Uma vez que a área 4 se caracteriza por abrigar pesquisadores que atuam e/ou possuem formação acadêmica tanto na área de educação em química quanto na área de química, a familiaridade dos mesmos com a questão da experimentação parece impulsionar a produção de trabalhos a respeito.

Entre 2004 e 2008 a produção na área 4 foi em torno de dois trabalhos por ano. Em 2009 foi observado um aumento significativo na produção: oito dissertações e uma tese. Em 2010 a produção de trabalhos voltou a diminuir e observamos um aumento substancial na produção novamente apenas no ano de 2012: oito dissertações e duas teses. Embora a produção de 43 trabalhos na área 4 seja digna de nota, esta tem ainda potencial para ser acentuada. Nesse sentido, é pertinente a observação de Maldaner (2013), sobre a necessidade de criação de núcleos de pesquisas em educação nos institutos/departamentos de química das universidades.

A defesa de dissertações e teses concernentes à experimentação no ensino de química, portanto, é contínua e irregular. Este resultado não é surpreendente, uma vez que a 
irregularidade na distribuição da produção acadêmica é uma característica da pesquisa em ensino de química e que tem sido relatada por outros autores, como Milaré e Rezende (2010). Estes apontam a escassez de trabalhos mais minuciosos sobre a área em questão, sugerindo a existência de lacunas ainda não amplamente exploradas. Nesse sentido, é possível especular que a escassez de pesquisas na área contribui para a irregularidade da produção mencionada.

\section{A produção e sua distribuição de acordo com a titulação acadêmica}

Os PPG estudados oferecem mestrado acadêmico, mestrado profissional e doutorado. Dentre os 143 trabalhos analisados, 85 são dissertações de mestrado acadêmico, 37 são dissertações do mestrado profissional e 21 são teses de doutorado. A Figura 2 ilustra a distribuição dos trabalhos de acordo com a titulação acadêmica e a área de produção.

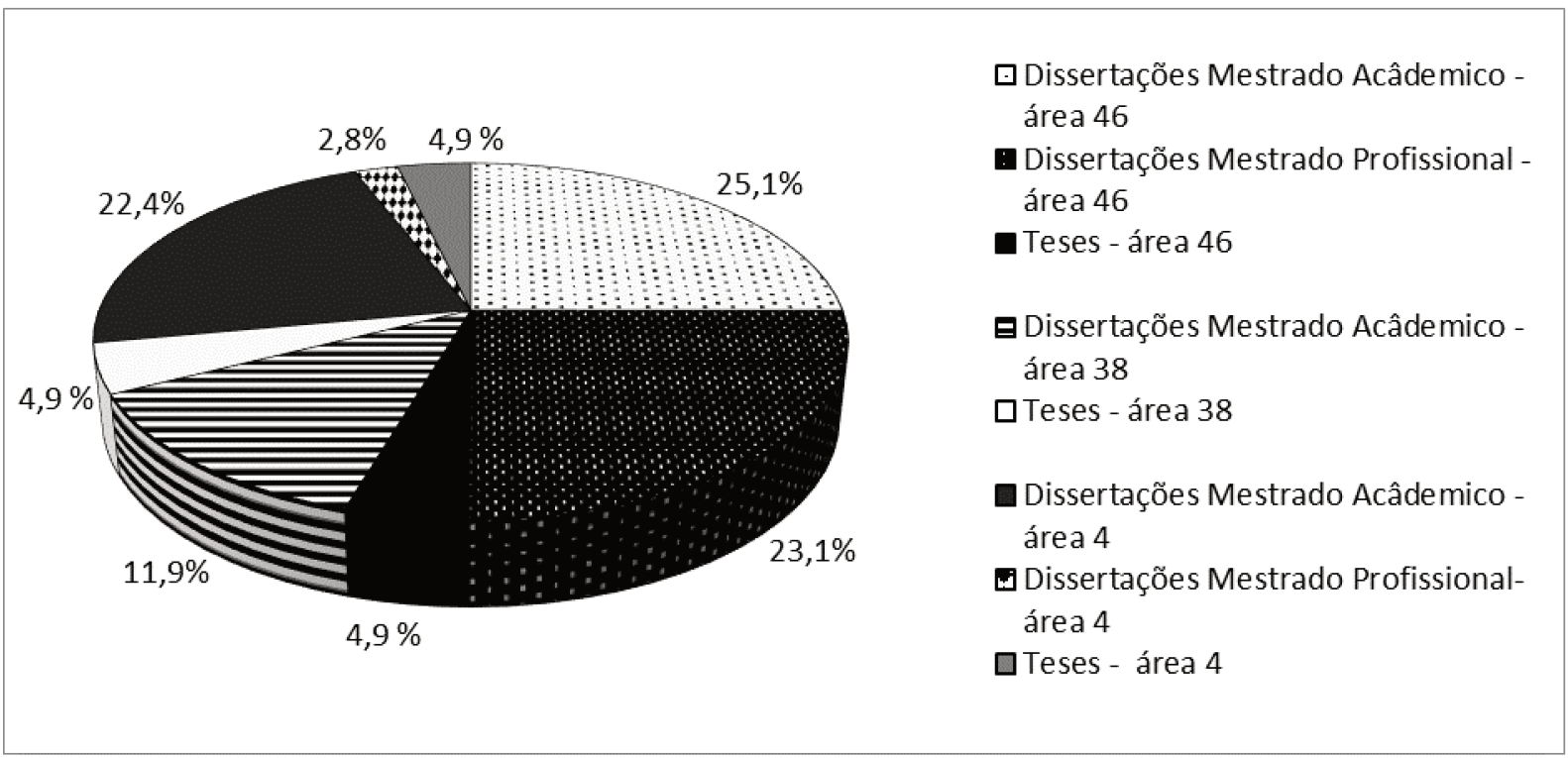

Figura 2 - Distribuição dos documentos de acordo com a titulação acadêmica e a área de produção, no período de 2004 a 2013

Fonte: Elaboração dos autores

As dissertações de mestrado acadêmico e profissional correspondem a 85,3\% da produção. Esse alto percentual pode ser atribuído, em parte, ao fato do primeiro credenciamento em nível de doutorado em PPG da área 46 ter ocorrido somente em 2001 (UFSC) e o segundo em 2003 (UNESP/Bauru). As primeiras teses sobre o tema em foco foram defendidas em 2009, nos PPG da UNESP/Bauru (KIOURANIS, 2009) e no PPG da UFSC (GONÇALVES, 2009). A área 46 contribuiu com sete teses ao todo. Estas são provenientes das seguintes PPG, que iniciaram suas atividades entre 2001 e 2009: UFBA (2006), UFRGS (2009), UFSC (2002), USP (2009), UNICSUL (2008) e UNESP/Bauru (2003).

A área 38 também gerou sete teses (SILVA, 2008; WALVY, 2008; DAVID; 2009; SILVA, 2009; MELO, 2010; NEVES, 2010; SOUZA, 2013). A produção de trabalhos ficou concentrada na UFMG, cujo programa de doutorado se iniciou em 1991, e contribuiu com 
quatro teses. Na USP, cujo programa de doutorado se iniciou em 1978, foram concluídas apenas duas teses. Na UFF, cujo PPG em nível de doutorado iniciou as atividades em 1995, foi concluída apenas uma tese. Nessa área, a primeira tese sobre o tema em foco foi defendida no PPG da UFMG (SILVA, 2008). Ou seja, aproximadamente no mesmo período daqueles da área 46.

Em relação à área 4, a produção de teses também foi pequena, apenas os PPG da USP, UFG, UFG-UFMS-UFU, UFSCar, UFRN, UNICAMP e UNESP/Araraquara contribuíram cada um com uma tese (TERCI, 2004; OLIVEIRA, 2009; SILVA JÚNIOR, 2010; FRANCISCO JÚNIOR, 2011; BÔSSO, 2012; SOUZA, 2012; GIBIN, 2013). Nessa área, a primeira tese foi defendida em 2004 no PPG da UNICAMP. A baixa produção de teses frente ao número de dissertações foi constatada em outros trabalhos do tipo estado da arte sobre a área de ensino de ciências e também de ensino de química. A constatação é alcançada mesmo em circunstâncias nas quais o volume da produção analisada é proveniente de PPG já consolidados e engloba intervalos de tempo extensos. Este predomínio foi verificado, por exemplo, nas investigações realizadas por Francisco, Alexandrino e Queiroz (2015), que analisaram 152 dissertações e duas teses defendidas sobre a educação em química em PPG da área 46, entre 2000 e 2008.

De acordo com Teixeira (2008), a explicação dessa disparidade no número de dissertações e teses defendidas pode ser relacionada à falta de interesse dos pós-graduandos na continuação dos seus estudos no doutorado ou pela opção por uma nova área de investigação durante o doutorado. Além disso, muitos pós-graduandos que fazem pesquisas dedicadas ao ensino de ciências são professores atuantes na escola básica, sem interesse profissional no doutorado, já que o título a ser adquirido não condiz a uma melhoria significativa de salário. Segundo Francisco, Alexandrino e Queiroz (2015), a evolução funcional pela via acadêmica gera benefícios, em termos salariais, que podem ser mais ou menos atrativos, de acordo com o estado da federação onde o professor atua.

A Figura 2 ilustra que a porcentagem da produção de dissertações de mestrado profissional $(23,1 \%)$ e de mestrado acadêmico $(25,1 \%)$ na área 46 é próxima. A temática da experimentação, portanto, tem sido alvo, com a mesma recorrência, de investigação tanto de pesquisadores que desejam seguir a vida acadêmica quanto de professores que buscam principalmente uma atualização profissional. Provavelmente, devido ao fato da realização de experimentos na educação básica estar acompanhada, muitas vezes, de impedimentos de várias ordens (conceitual ou material), a investigação a seu respeito seja atrativa aos professores, no sentido de conseguir meios para superar esse obstáculo.

De acordo com Moreira (2007), o mestrado profissional possui características que o diferencia do mestrado acadêmico. O primeiro pretende o aperfeiçoamento da formação 
profissional e o segundo é direcionado para a pesquisa acadêmica. Dentre os 88 PPG alocados na área 46 , que podem abarcar trabalhos voltados à experimentação no ensino de química, 49 PPG são de mestrado profissional, porém identificamos trabalhos sobre o tema em foco somente em nove PPG de quatro regiões geográficas, sendo que a maioria está localizada na região Centro-Oeste. A Tabela 1 apresenta a distribuição das 33 dissertações de mestrado profissional, de acordo com os PPG da área 46.

Tabela 1 - Distribuição das dissertações de mestrado profissional da área 46 de acordo com o ano de defesa e região geográfica no período de 2004 a 2013

\begin{tabular}{|c|c|c|c|c|c|c|c|c|c|c|c|}
\hline \multicolumn{2}{|c|}{$\begin{array}{c}\text { MESTRADO } \\
\text { PROFISSIONAL }\end{array}$} & \multicolumn{10}{|c|}{$\begin{array}{c}\text { NÚMERO DE DISSERTAÇÕES DE ACORDO COM } \\
\text { O ANO DE DEFESA }\end{array}$} \\
\hline REGIÃO & IES & ذ్ & 串 & $\overbrace{\bar{I}}^{2}$ & క్రి & ڤ్రి & $\widehat{\widehat{亏}}$ & 융 & $\bar{\Xi}$ & $\frac{\text { บิ }}{8}$ & $\stackrel{\text { m }}{\overline{2}}$ \\
\hline \multirow[t]{2}{*}{ NORDESTE } & UFC & - & - & - & - & - & - & - & - & 2 & 1 \\
\hline & UFRN & - & - & - & - & - & - & 2 & - & - & - \\
\hline \multirow{3}{*}{$\begin{array}{l}\text { CENTRO- } \\
\text { OESTE }\end{array}$} & UFMT & - & - & - & - & - & - & - & - & - & 1 \\
\hline & UFMS & - & - & - & - & - & - & 1 & 1 & - & - \\
\hline & UnB & & - & 2 & 1 & 2 & 2 & - & 2 & 4 & 4 \\
\hline \multirow[t]{2}{*}{ SUDESTE } & UNIFOA & - & - & - & - & - & - & - & 1 & - & - \\
\hline & UNIGRANRIO & & & & & & & & 1 & 1 & 1 \\
\hline \multirow[t]{2}{*}{ SUL } & UNIVATES & & & & & & & & & 2 & \\
\hline & UTFPR & & & & & & & & & 1 & 1 \\
\hline
\end{tabular}

Fonte: Elaboração dos autores

Quanto à área 4, esta possui apenas um PPG que se caracteriza como mestrado profissional: ensino de química da UFSCar. Neste PPG foram defendidas quatro dissertações no período investigado sobre a temática em questão, a primeira em 2011 (SILVA, 2011), a segunda em 2012 (SILVA, 2012) e as demais em 2013 (RUSSO, 2013; ZANDONAI, 2013). No que se refere à área 38 , não localizamos trabalhos sobre a temática investigada em nenhum PPG. A expectativa, porém, é que estes venham a ser produzidos nos próximos anos, uma vez que a ampliação no número de mestrado profissional em educação, de 26 no ano de 2013 para 44 em 2016, indica a crescente tendência de produção de documentos dessa natureza (CAMPOS; GUÉRIOS, 2017).

As duas primeiras dissertações defendidas no mestrado profissional sobre o tema em foco ocorreram em 2006 e são originárias do PPG da UnB, que foi reconhecido pela CAPES em 2004. Após esse período, o PPG produziu uma média de dois trabalhos por quatro anos consecutivos, o que coloca o mestrado profissional dessa instituição em destaque frente aos demais, com a produção de dezessete dissertações. De fato, nos demais PPG desse tipo não foram produzidos mais do que quatro trabalhos no período investigado. Mesmo o PPG da 
UFRN, reconhecido um ano antes do $\mathrm{PPG}$ da $\mathrm{UnB}$, não teve produção tão contínua. Provavelmente, contribuiu para a produção significativa e consolidação do PPG da UnB o fato de reunir orientadores que são pioneiros na área de pesquisa em educação em química, como Roberto Ribeiro da Silva, ou que nela atuam fortemente, como Gerson de Souza Mól, autor de livro presente no Guia de Livros Didáticos de Química do PNLD (Programa Nacional do Livro Didático, 2015).

Nesse contexto, é possível sugerir que a modalidade do mestrado profissional tem potencial para trazer contribuições importantes para o aprimoramento das práticas de ensino na área de química, em particular daquelas que envolvem a experimentação. Concordamos, portanto, com Fialho e Hetkowski (2017, p. 19), quando afirmam que trabalhos produzidos nessa modalidade tendem a "contemplar relações entre educação superior e educação básica, mundo acadêmico e setor produtivo, setor público e setor privado, educação e formação de trabalhadores, nas mais diversas práticas sociais".

\section{A produção e sua distribuição de acordo com a região geográfica e instituição de origem}

A distribuição da produção acadêmica de acordo com as respectivas áreas está apresentada na Figura 3.

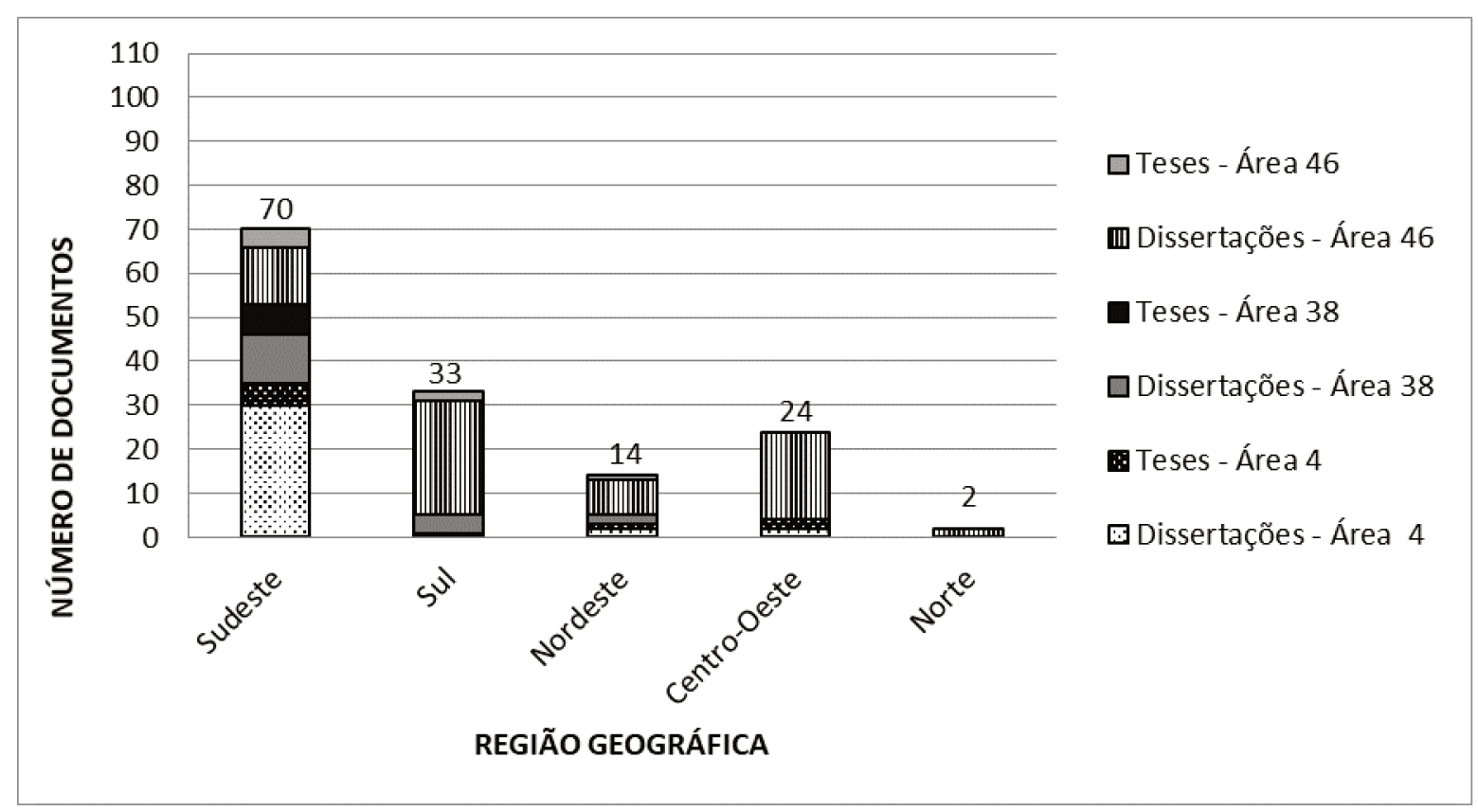

Figura 3 - Distribuição das dissertações e teses de acordo com a região geográfica e área de produção, no período de 2004 a 2013

Fonte: Elaboração dos autores

Conforme observado na Figura 3, a região Sudeste concentra a maioria dos trabalhos: 55 dissertações e quinze teses. A região Sul contribuiu com 33 trabalhos desenvolvidos em 13 PPG, distribuídos nos três estados pertencentes a esta região. Cabe destacar que a elevada concentração de dissertações e teses nas regiões Sudeste e Sul sobre o tema em foco foi 
igualmente apontada por Gonçalves e Marques (2012b). Os autores verificaram que grande parte da produção correspondente às dezoito dissertações sobre experimentação defendidas entre 1972 e 2006 era também proveniente das referidas regiões. No início da década, Schnetzler (2002) justificava tal constatação com base no conhecimento de que parte significativa dos orientadores de mestrado e doutorado na área atuavam nessas regiões. Em um trabalho mais recente, Francisco (2011) demonstra que essa tendência permanece.

$\mathrm{Na}$ região Centro-Oeste foram finalizados 24 documentos em cinco diferentes PPG existentes no Distrito Federal e em três estados, o que é digno de nota. De fato, os resultados encontrados por Gonçalves e Marques (2012b), com relação a trabalhos sobre experimentação no período de 1972 a 2006, não indicavam nenhuma produção na região, devido à escassez de grupos de pesquisa. Somente em 2004 o PPG em ensino de ciências da UnB foi reconhecido pela CAPES, o que levou à produção dos primeiros trabalhos sobre experimentação, a partir de 2006. No PPG em questão, foram localizados dezessete trabalhos ao todo, indicando a consolidação do Laboratório de Pesquisa e Ensino de Química da UnB. Tal consolidação também é evidente a partir da discussão realizada no artigo intitulado "Laboratório de Pesquisas em Ensino de Química da Universidade de Brasília - LPEQ/UnB: concepções, relatos e reflexões" (SILVA et al., 2011).

A região Nordeste contribuiu com doze dissertações e duas teses, distribuídas em oito PPG das áreas 46, 38 e 4, presentes em quatro estados. Com relação à região Norte, foram produzidos apenas dois trabalhos. Para tentar superar a situação de escassez de pesquisas nessa região, em 2014 foi elaborada a Carta de Rio Branco.

O conteúdo da Carta de Rio Branco abarcou a apresentação, por parte dos PPG da área de Ensino na Amazônia Legal, à Presidência da CAPES e aos demais organismos concernentes ao ensino superior do país, os pleitos e proposições para superação de dificuldades que surgiram da avaliação realizada, a fim de garantir apoio à consolidação dos PPG já existentes, e ampliação da oferta de novos PPG em Ensino, fortalecendo assim, direta e indiretamente a educação básica na região amazônica. Na referida Carta, foi reivindicado o fortalecimento da REAMEC (Rede Amazônica de Matemática e Ensino de Ciências), a mais importante Rede já construída pela área para ampliar a formação de doutores na região.

Em relação à área 46 , todas as regiões do país contribuíram com a produção de trabalhos sobre experimentação no ensino de química. Quanto à área 38, existem trabalhos na região Sudeste, Sul e Nordeste, sendo que a maior produção foi na região Sudeste. Em contraponto, não houve produção sobre a temática em estudo nas regiões Centro-Oeste e Norte. Quanto à área 4, ocorreu a contribuição de todas as regiões do país na produção de trabalhos sobre a temática em foco, com exceção da região Norte. Tal fato pode ser 
justificado, pela ausência de grupos de pesquisa voltados à educação em química atuando nos PPG de química dessa região.

A distribuição das dissertações e teses de acordo com as 38 IES de origem se encontra apresentada na Tabela 2.

Tabela 2 - Distribuição absoluta das dissertações e teses de acordo com a IES e a área, no período de 2004 a 2013

\begin{tabular}{|c|c|c|c|c|c|c|c|c|c|}
\hline \multirow[t]{2}{*}{ IES } & \multicolumn{4}{|c|}{$\begin{array}{c}\text { Número de documentos por } \\
\text { área }\end{array}$} & \multirow[t]{2}{*}{ IES } & \multicolumn{4}{|c|}{$\begin{array}{c}\text { Número de documentos por } \\
\text { Área }\end{array}$} \\
\hline & 46 & 38 & 4 & Totais & & 46 & 38 & 4 & Totais \\
\hline USP & 07 & 04 & 07 & 18 & UEM & 02 & - & - & 02 \\
\hline UnB & 17 & - & - & 17 & UFSC & 02 & - & - & 02 \\
\hline UFSCar & - & 04 & 11 & 15 & UFPA & 02 & - & - & 02 \\
\hline UNICAMP & - & - & 10 & 10 & UFBA & 02 & - & - & 02 \\
\hline $\begin{array}{l}\text { UFRGS-UFSM } \\
\text {-FURG }\end{array}$ & 09 & - & - & 09 & UNIJUI & - & 02 & - & 02 \\
\hline UNESP & 04 & 01 & 03 & 08 & UFS & 01 & - & - & 01 \\
\hline UFRN & 02 & 01 & 03 & 06 & UNISANTOS & - & 01 & - & 01 \\
\hline PUC/RS & 05 & - & - & 05 & FURB & - & 01 & - & 01 \\
\hline UFMG & - & 05 & - & 05 & UNIFOA & 01 & - & - & 01 \\
\hline UNIGRANRIO & 03 & - & - & 03 & CEFET/RJ & 01 & - & - & 01 \\
\hline UEL & 03 & - & - & 03 & UFMT & 01 & - & - & 01 \\
\hline UFC & 03 & - & - & 03 & $\begin{array}{l}\text { UFG-UFMS- } \\
\text { UFU }\end{array}$ & - & - & 01 & 01 \\
\hline UFU & - & - & 03 & 03 & UFAL & - & 01 & - & 01 \\
\hline ULBRA & 03 & - & - & 03 & UFF & & 01 & & 01 \\
\hline PUC/SP & - & 02 & - & 02 & UNIFRAN & - & - & 01 & 01 \\
\hline UFG & - & - & 03 & 03 & UNISUL & - & 01 & - & 01 \\
\hline UFMS & 02 & - & - & 02 & UNICENTRO & - & - & 01 & 01 \\
\hline UTFPR & 02 & & & 02 & UNICSUL & 01 & & & 01 \\
\hline \multirow[t]{2}{*}{ UNIVATES } & 02 & - & - & 02 & UFRPE & 01 & & & 01 \\
\hline & & & & & Totais & 76 & 24 & 43 & 143 \\
\hline
\end{tabular}

Fonte: Elaboração dos autores

A análise dos dados expostos na Tabela 2 indica a liderança da USP, com 12,6\% do total da produção investigada, seguida pela UnB, com 12,0\%, e pela UFSCar com $10,5 \%$.

Trabalhos sobre o estado da arte na educação em ciências costumam justificar a produção acentuada de documentos da USP com base no fato do início das atividades do PPG da área 46 ter ocorrido em 1973 na modalidade ensino de física. A ampliação de suas atividades aconteceu em 1998, com o início da modalidade ensino de química, e em 2005 
com o início da modalidade ensino de biologia. Ademais, a partir de 2009, o PPG passou também a oferecer estudos no nível de doutorado. Outro aspecto atribuído que justifica o destaque da IES é o fato de apresentar em seus quadros orientadores pioneiros na área e lideranças emergentes (FRANCISCO, 2011).

Milaré (2013) afirma que o número de dissertações e teses defendidas na USP na área de ensino de química duplicou entre os anos de 2005 e 2009. Até 2004 foram defendidas, no total, trinta dissertações e teses, enquanto esse número passou para 65 no período de 2005 a 2009. Segundo o autor, esses trabalhos foram produzidos em PPG nas três áreas - educação, química e ensino de ciências - distribuídos em dois campi da USP (São Paulo e São Carlos). Nessa perspectiva, os resultados provenientes deste trabalho estão alinhados com os reportados pelo autor: a existência um grande número de trabalhos sobre experimentação no ensino de química nessa instituição, distribuídos nas áreas 46, 38 e 4, como pode ser observado na Tabela 1.

A UnB foi a segunda IES a contribuir com o maior número de trabalhos, todos pertencentes ao PPG vinculado à área 46. A produção contínua de trabalhos da UnB a partir de 2006, ou seja, dois anos após a recomendação do PPG pela CAPES, reforça a observação feita anteriormente sobre a consolidação de grupos de pesquisas na região Centro-Oeste.

A UFSCar contribuiu com 10,5\% da produção, com destaque para o PPG da área 4, no qual foram finalizados onze trabalhos (dez dissertações e uma tese). Dentre as dissertações, quatro se relacionam com o mestrado profissional em ensino de química que iniciou suas atividades em 2008. Já os outros trabalhos foram finalizados pelo PPG em Química que iniciou suas atividades na década de 1980.

A UNICAMP, UFRGS-UFSM-FURG e UNESP contribuíram respectivamente com $7,0 \%, 6,2 \%$ e $5,6 \%$ da produção total. Os trabalhos da UNICAMP pertencem a PPG vinculado à área 4, que deu início às suas atividades em 1972. Já os trabalhos da UFRGSUFSM-FURG fazem parte da área 46. O PPG da UFRGS, em 2008, se associou a duas outras instituições da região Sul, a UFSM e FURG, e a partir de então passou a ser constituído pelas três IES. A UNESP apresentou trabalhos em todas as áreas, com destaque para área 46, com o maior número de trabalhos, quatro ao todo. O referido PPG iniciou suas atividades em $1997 \mathrm{e}$ nele foi finalizada a primeira tese dos PPG alocados nesta área. Ainda merecem destaque as atuações da UFRN com seis trabalhos e a PUC/RS e UFMG, com a produção de cinco trabalhos cada uma por IES.

Na Tabela 2 pode ser observado que quatorze PPG contribuíram com um trabalho somente. Como já mencionado anteriormente, alguns desses PPG já estão consolidados, porém, tiveram uma pequena participação na produção de trabalhos sobre o tema em foco. $\mathrm{O}$ predomínio de instituições estaduais e federais como locais de produção dos documentos 
também é evidenciado. De fato, 27 dentre as 38 IES de origem das dissertações e teses são dessa natureza, perfazendo um total de $84,6 \%$ da produção. Os demais PPG são de natureza privada e perfazem o total de $15,4 \%$ da produção. Assim, os dados confirmam o papel central das instituições públicas no desenvolvimento da Pós-Graduação no país, constatado também, em trabalhos mais amplos que tratam de questões inerentes a este nível de ensino. De fato, Ciriani et al. (2015) constataram que, em 2011, a maioria dos doutores e mestres obtiveram seus títulos em instituições públicas: para o doutorado, $89,5 \%$ dos títulos foram obtidos em instituições públicas, contra 10,5\% obtidos em instituições privadas.

\section{A produção e sua distribuição de acordo com o nível escolar}

As dissertações e teses foram analisadas com relação ao nível escolar, levando a cabo para a sua classificação características como os relatos educacionais retratados, os materiais didáticos utilizados, os programas de ensino apresentados e os participantes da pesquisa. A distribuição dos documentos por nível de escolaridade conforme ano de defesa está apresentada na Tabela 3. Foram utilizados como base para cálculo os 143 documentos analisados para a obtenção dos percentuais de representatividade.

Tabela 3 - Distribuição das dissertações e teses de acordo com nível escolar abrangido, ano de defesa e a área de produção no período de 2004 a 2013

\begin{tabular}{|c|c|c|c|c|c|c|c|c|c|c|c|c|c|}
\hline \multirow[t]{2}{*}{ Ano } & \multicolumn{3}{|c|}{$\begin{array}{l}\text { Médio/ } \\
\text { Área }\end{array}$} & \multicolumn{3}{|c|}{$\begin{array}{l}\text { Superior/ } \\
\text { Área }\end{array}$} & \multicolumn{3}{|c|}{$\begin{array}{c}\text { Fundamental/ } \\
\text { Área }\end{array}$} & \multicolumn{3}{|c|}{ Geral } & \multirow[t]{2}{*}{ Total } \\
\hline & 46 & 38 & 4 & 46 & 38 & 4 & 46 & 38 & 4 & 46 & 38 & 4 & \\
\hline 2004 & 5 & - & 1 & & & 2 & 1 & 1 & & & & & 10 \\
\hline 2005 & 2 & 1 & 1 & & & 2 & 1 & & & 1 & & & 8 \\
\hline 2006 & 2 & 1 & 3 & & & 1 & & & 1 & & & & 8 \\
\hline 2007 & 4 & & & 1 & & 1 & & & & & & 1 & 7 \\
\hline 2008 & 6 & 4 & 2 & 2 & & & & & & & & & 14 \\
\hline 2009 & 4 & 5 & 8 & 2 & 1 & & & & 1 & & & & 21 \\
\hline 2010 & 3 & 3 & - & 3 & 2 & 3 & & 1 & & & & & 15 \\
\hline 2011 & 9 & 1 & 2 & 1 & & 2 & 1 & & & 1 & 1 & & 18 \\
\hline 2012 & 11 & & 6 & 5 & 1 & 4 & & & 1 & & & & 28 \\
\hline 2013 & 11 & 1 & 2 & 3 & 1 & 2 & 2 & & & & & & 22 \\
\hline Total & 57 & 16 & 25 & 17 & 5 & 17 & 5 & 2 & 3 & 2 & 1 & 1 & 151 \\
\hline \multirow[t]{2}{*}{$(\%)$} & 39,8 & 11,2 & 17,5 & 11,9 & 3,5 & 11,9 & 3,5 & 1,4 & 2,1 & 1,4 & 0,7 & 0,7 & \multirow{2}{*}{105,6} \\
\hline & & 68,5 & & & 27,3 & & & 7 , & & & 2,8 & & \\
\hline
\end{tabular}

Fonte: Elaboração dos autores

Como pode ser observado na Tabela 3, o número total de trabalhos localizados ultrapassa 143 dissertações e teses, já que oito documentos foram classificados em mais de 
um nível de escolaridade. Os trabalhos sobre experimentação que abordaram o ensino médio perfazem 90 documentos. Quando adicionamos a esse número os documentos que tratam o ensino médio em conjunto com outros níveis um total de 98 documentos é alcançado: um é referente ao ensino fundamental e médio e sete referentes ao ensino médio e superior, o que perfaz $68,5 \%$ dos trabalhos analisados. Um aumento na produção é observado em 2008 e 2009, apresentando uma queda em 2010, mas a produção volta a se estabilizar novamente entre 2011 e 2013, com uma média aproximada de 22 trabalhos em cada ano desse período.

As temáticas abordadas nesses estudos, entre outras, foram: utilização de abordagem histórica e experimentação para ensinar conceitos de química no ensino médio (POPPOLINO, 2013) e habilidades cognitivas de alunos do ensino médio na realização de atividades experimentais investigativas (SUART, 2008).

Observa-se que as investigações sobre experimentação realizadas no ensino médio envolvem, basicamente, o uso de estratégias de ensino e a forma com a qual os alunos aprendem a partir das mesmas. Por fim, as pesquisas também abordam aspectos relacionados às dificuldades que os professores apresentam em relação à condução das atividades experimentais. Ou seja, as pesquisas nesse nível são direcionadas a aspectos que podem melhorar a aprendizagem dos alunos por meio da experimentação, considerando inclusive a forma como o professor ensina.

Quanto à maior produção de trabalhos abordando a experimentação no ensino médio, Gonçalves e Marques (2012b) sugerem que o fato da experimentação na educação básica ser mais investigada nas dissertações e teses do que a atividade experimental na educação superior se deve à quase ausência de experimentos no ensino médio e fundamental. O que não ocorre, obviamente, no ensino superior de química, quando os alunos são requisitados a realizar experimentos em várias disciplinas.

No que tange à produção de dissertações e teses voltadas ao ensino superior, 39 trabalhos $(27,3 \%$ do total da produção), considerando os sete trabalhos que abordaram em conjunto o ensino médio, foram finalizados no intervalo de investigação desta pesquisa, A maior produção ocorreu em 2012, com dez trabalhos. Os autores que privilegiaram esse nível de ensino, em sua maioria, desenvolveram: investigações sobre interação verbal e atividade prática investigativa, como proposta para repensar a formação inicial de professores de química (ORNELLAS, 2012) e propostas de atividades experimentais demonstrativoinvestigativas que podem ser acessadas a partir de ambiente virtual (PHILIPPSEN, 2012)

O ensino fundamental, em contraponto, foi pouco investigado (apenas dez trabalhos foram produzidos) e na educação infantil nenhum trabalho foi localizado. Os trabalhos que abordam o ensino fundamental representam apenas $7,0 \%$ do total da produção, considerando 
um deles que aborda em conjunto o nível médio. O baixo número de trabalhos abordando o nível fundamental ilustra a pouca atenção dada a esse nível de ensino.

Em relação ao ensino fundamental, a baixa produção de trabalhos não é surpreendente, pois essa constatação já é de longa data (SANTOS, 2001). A existência de poucos estudos e a ausência de pesquisas direcionadas à educação infantil pode ser justificada com base no fato da introdução de tópicos relacionados ao ensino de química ocorrer, usualmente, apenas nos últimos anos desse nível escolar e de forma bastante condensada. Em contraponto, de acordo com Mori e Curvelo (2014), mesmo nos primeiros anos do ensino fundamental é possível abordar noções básicas de química (como fotossíntese, combustão e decomposição da matéria orgânica). Essa lacuna poderia ser preenchida caso o direcionamento para a realização de atividades experimentais ocorresse de forma distinta da atual, em que são privilegiados conteúdos de biologia.

A baixa produção de trabalhos sobre experimentação no ensino de química nos anos iniciais do ensino fundamental pode estar relacionada também à formação inicial e continuada de professores que atuam nesse nível de ensino. Constata-se, assim, a necessidade desses professores participarem de cursos de formação continuada que possibilitem e estimulem a reflexão da sua própria prática e ofereça subsídios para que lidem com questões vinculadas ao ensino de química.

\section{A produção e sua distribuição de acordo com o foco temático}

As dissertações e teses produzidas que apresentam a experimentação como tema principal de pesquisa também foram analisadas com relação aos focos temáticos. Assim como realizado por Silva et al. (2017), foi identificado em cada trabalho selecionado o foco principal de investigação. Para tanto, foi realizada uma leitura de forma indutiva, para além da leitura flutuante, tecendo considerações e realizando ajustes no seu decorrer. Dessa maneira, as categorias construídas emergiram a partir das características dos textos investigados e não de uma literatura específica. Conforme afirmam os autores supracitados, "o resultado passa a ser uma particularidade do conjunto de trabalhos analisados, constituindo uma representação que leva em conta a percepção do pesquisador frente ao corpus" (SILVA et al., 2007, p. 685).

Partindo desse pressuposto, foram tomados como base para cálculo nesta etapa 84 trabalhos classificados em destaque, sendo que cinco deles foram classificados em mais de um foco. A Figura 4 apresenta a distribuição dos trabalhos de acordo com os focos temáticos elaborados, assim como a área de produção. 


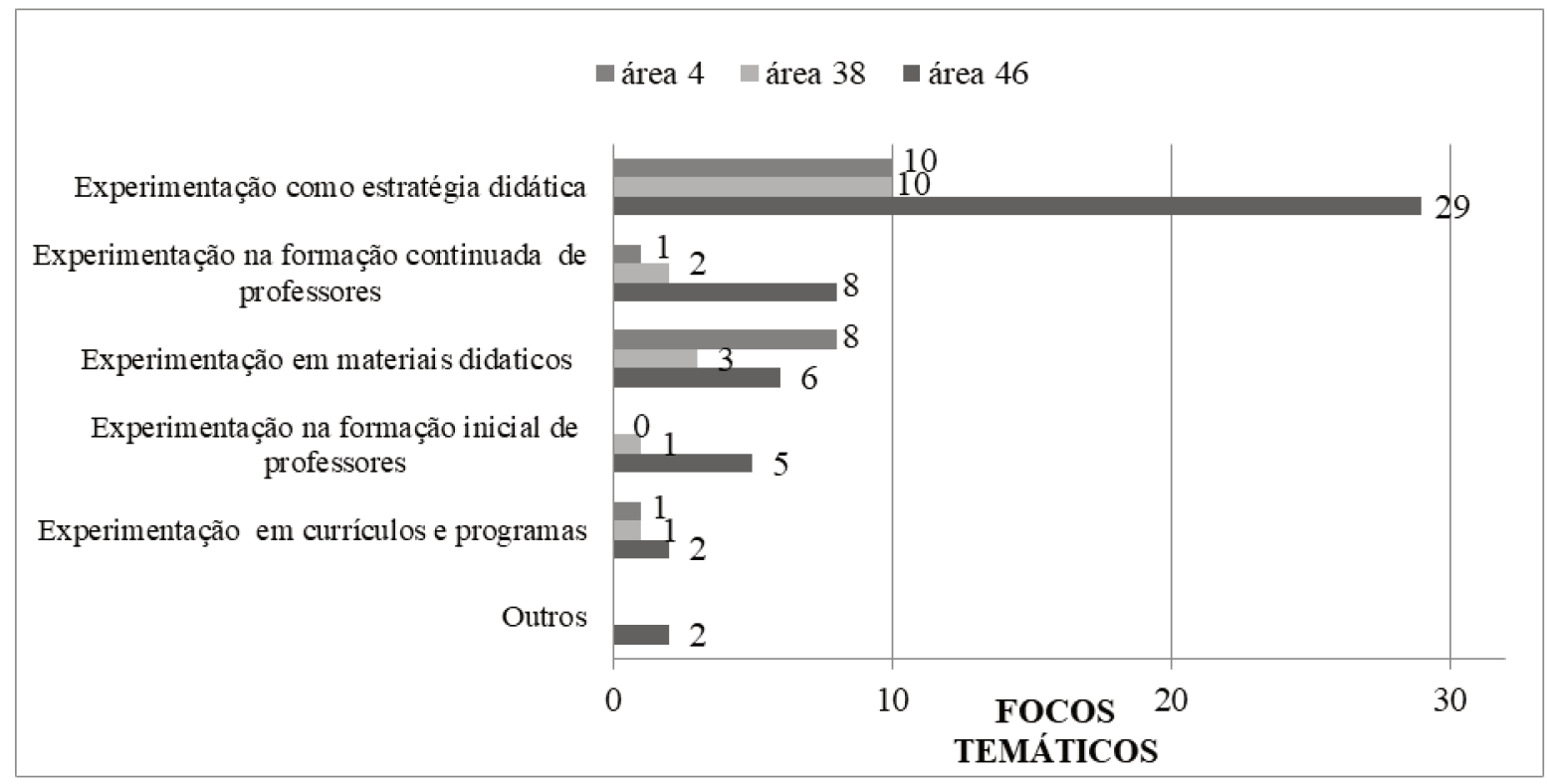

Figura 4 - Distribuição das dissertações e teses de acordo com o foco temático abordado e a área de produção, no período de 2004 a 2013

Fonte: Elaboração dos autores

Conforme os dados apresentados na Figura 4, dentre os documentos considerados, 49 $(58,3 \%)$ abordam a experimentação como estratégia didática e dezessete $(20,2 \%)$ abordam a experimentação em materiais didáticos. No que diz respeito à formação de professores, onze $(13,1 \%)$ abordam a experimentação na formação continuada e seis $(7,1 \%)$ na formação inicial. Foram menos privilegiados os trabalhos que abordam a experimentação em currículos e programas, totalizando quatro ocorrências $(4,8 \%)$. Por fim, dois trabalhos foram classificados no foco outros $(2,4 \%)$.

No foco experimentação como estratégia didática foram colocados tanto os trabalhos com ênfase como aqueles sem ênfase na construção do conhecimento químico. No foco experimentação em materiais didáticos os trabalhos encontrados se associam à análise de livros didáticos, elaboração de materiais didáticos e elaboração e aplicação de materiais didáticos. No foco experimentação na formação continuada de professores foram encontrados trabalhos relacionados às ações de formação continuada e às características do professor. No foco experimentação na formação inicial de professores os trabalhos tratam das características do licenciando e das características do professor formador. No foco experimentação em currículos e programas os trabalhos encontrados versaram acerca das atividades experimentais no contexto de cursos específicos de graduação em química e atividades experimentais no contexto dos primeiros anos da educação escolar.

O foco experimentação como estratégia didática foi o mais abordado nas três áreas, seguido do foco experimentação em materiais didáticos, para as áreas 38 e 4, revelando o interesse dos pesquisadores em desenvolver distintas abordagens que utilizam a experimentação. Em contraponto, pouca atenção é dada às pesquisas relacionadas ao foco 
experimentação em currículos e programas e também é baixa a produção sobre a experimentação na formação de professores, na qual a área 46 se destaca perante as demais.

Em linhas gerais, o exame das dissertações e teses aqui realizado corrobora os resultados encontrados por Gonçalves e Marques (2012b), que analisaram dezoito pesquisas realizadas em PPG stricto sensu, no período entre 1972 e 2006. Os autores constataram que a experimentação no ensino de química tem sido entendida, principalmente, "como uma possibilidade metodológica para favorecer a aprendizagem dos conteúdos" (p. 198), sendo ainda pouco articulada com a formação de professores e com outras temáticas.

\section{Considerações finais}

A reunião dos 143 documentos indicou que a produção sobre o assunto é contínua e irregular, com uma tendência ao crescimento no período de 2004 a 2013. Tal crescimento está associado, principalmente, ao processo de expansão e consolidação de PPG da área 46, de onde se origina a grande maioria dos documentos. É também significativa a produção proveniente de PPG da área 4, que, diferentemente do observado nos PPG da área 46, abriga pesquisadores atuantes na área de Química, usualmente familiarizados ou que lidam no seu dia a dia com a questão da experimentação, o que parece impulsionar a realização de pesquisas a respeito. Em contraponto, foi bastante reduzido o número de documento oriundos de PPG da área 38, frente aos demais PPG, sugerindo o pouco interesse despertado pela temática entre os pesquisadores que a eles estão vinculados.

Quanto à titulação acadêmica, observamos um predomínio na produção de dissertações de mestrado, o que pode ser justificado tendo em vista que nos PPG onde está concentrada a produção mais significativa, os da área 46, o primeiro credenciamento em nível de doutorado ocorreu somente em 2001, enquanto os credenciamentos em nível de mestrado são muito anteriores a essa data. Outra justificativa pode ser oferecida a partir do conhecimento amplamente difundido de que muitos pós-graduandos que fazem pesquisas dedicadas ao ensino de ciências são professores atuantes na escola básica, sem interesse profissional no doutorado. Ainda com relação à titulação acadêmica, chama atenção o fato de, na área 46, ser muito próxima a porcentagem da produção de dissertações de mestrado profissional e de mestrado acadêmico, indicando a relevância da contribuição dessa mais nova modalidade de mestrado para a geração de conhecimentos sobre a experimentação no ensino de química, com destaque para o mestrado profissional em ensino de ciências da UnB, responsável por mais da metade da produção de dissertações desse tipo.

Embora a produção de trabalhos encontre-se distribuída em todas as regiões geográficas brasileiras, concentra-se fortemente na região Sudeste. Destacam-se também as regiões Sul e Centro-Oeste, com produção bem menos vigorosa nas regiões Nordeste e Norte. 
Resultado este que não é surpreendente e pode ser parcialmente explicado com base na baixa densidade de PPG, especialmente na região Norte. De fato, segundo Ciriani et al. (2015), em 2011, de um total de 4650 PPG, 51\% estavam na região Sudeste e somente $4 \%$ na região Norte.

O principal centro de produção de dissertações e teses sobre experimentação no ensino de química é a USP, com destaque para o PPG Interunidades em Ensino de Ciências, área 46, e o PPG em Química do IQSC, área 4. A UnB foi a segunda IES com maior contribuição na produção, sendo toda ela proveniente do mestrado profissional em ensino de ciências. $\mathrm{O}$ estabelecimento de comparação entre a produção das duas IES reafirma a relevância da contribuição dos mestrados do tipo profissional para o desenvolvimento de pesquisas sobre a temática, uma vez que toda a produção dos três PPG da USP (onde não constam mestrados profissionais) se iguala ao do único PPG da UnB. Nessa perspectiva, pode-se aventar a hipótese de que a elevada concentração de dissertações do mestrado profissional sobre a temática se deve ao fato da realização de experimentos na educação básica estar acompanhada, muitas vezes, de impedimentos de ordem conceitual ou material, sendo a investigação a seu respeito atrativa para professores, que assumem o papel de pósgraduandos, nos mestrados profissionais.

Com relação ao nível escolar abrangido, constatamos que os estudos sobre experimentação voltados ao ensino médio prevaleceram, seguidos pelo ensino superior e ensino fundamental. Não foram localizados estudos voltados à educação infantil, o que não significa que sejam pouco plausíveis pesquisas neste nível de ensino. O número também reduzido de trabalhos no ensino fundamental aponta para outra lacuna que carece de preenchimento, uma vez que é importante introduzir a química nos primeiros anos do ensino fundamental, principalmente quando temos em mente a formação de cidadãos "quimicamente alfabetizados" e esse é o único nível de escolaridade para uma grande parte da população brasileira.

Os focos privilegiados nas dissertações e teses analisadas foram experimentação como estratégia didática e experimentação em materiais didáticos. Em um número menor de trabalhos foi abordada a experimentação na formação inicial e continuada de professores. Dois outros focos identificados tiveram baixa recorrência: experimentação em currículos e programas e outros.

Por fim, acreditamos que a construção de um panorama geral sobre a produção acadêmica a respeito da experimentação no ensino de química no Brasil foi alcançada a partir da realização deste trabalho e julgamos relevante que novos esforços de pesquisa sejam envidados, tendo em vista o aprofundamento de muitos aspectos aqui mencionados, tais como a análise do grau de direcionamento e dos conteúdos químicos presentes nas estratégias 
didáticas citadas, assim como os recursos envolvidos nas propostas experimentais, como o tipo de material utilizado e a presença de roteiros. Entendemos também a importância do quadro teórico para a consolidação e reconhecimento de estudos acadêmicos, de modo que a investigação sobre a base teórica e conceitual presente nas dissertações e teses poderia trazer valiosa contribuição para o progresso das discussões sobre o tema.

\section{Referências}

BÔSSO, A. R. S. A. Desenvolvimento do software PlanEx de planejamento de experimentos online e sua aplicação didática na pós-graduação. Tese de doutorado em Química Universidade Federal de Goiás, Goiânia, 2012.

CAMPOS, M. A. T.; GUÉRIOS, E. Mestrado profissional em educação: reflexões acerca de uma experiência de formação à luz da autonomia e da profissionalidade docente. Educar em Revista, n. 63, p. 35-51, 2017.

\section{CAPES. COORDENAÇÃO DE APERFEIÇOAMENTO DE PESSOAL DE NÍVEL} SUPERIOR. Portaria Conjunta ${ }^{\circ} 02$ de 13 de setembro de 2011. Chamada Pública MCTI/CNPq/MEC/Capes - Ação Transversal n06/2011 - Casadinho/Procad, 2011. Disponível em: <http://www.capes.gov.br/images/stories/download/legislacao/PortariaConjunta-n-2-CAPES-CNPq-13-9-2011.pdf.2011a_>. Último acesso em: 26 mar. 2016.

CÉSAR, J. Material instrucional para química geral experimental: uma contribuição à universidade aberta do Brasil. Dissertação de mestrado em Química - Universidade Estadual de Campinas, Campinas, 2008.

CIRIANI, C. B. S.; CAMPANARIO, M. A.; SILVA, H. H. M. A evolução do ensino da pósgraduação senso estrito no Brasil: análise exploratória e proposições para pesquisa. Avaliação, v. 20, n. 1 , p. 163-187, 2015.

DAVID, M. A. Processos de evolução conceitual em química no contexto das atividades experimentais. Tese de doutorado em Educação - Universidade Federal de Minas Gerais, Belo Horizonte, 2009.

FERREIRA, N. S. A. As pesquisas denominadas "Estado da Arte". Educação \& Sociedade, v. 23 , n. 79, p. 257-272, 2002.

FERREIRA, H. H. J.; AMARAL, C. L. C. Pesquisa em ensino de química experimental: mapeamento das teses e dissertações apresentadas no Brasil de 2002 a 2011. Revista Brasileira de Ensino de Ciência e Tecnologia, v. 8, n. 1, p. 20-35, 2015.

FIALHO, N. H.; HETKOWSKI, T. M. Mestrados profissionais em educação: novas perspectivas da pós-graduação no cenário brasileiro. Educar em Revista, n. 63, p. 19-34, 2017.

FRANCISCO, C. A. Análise de dissertações e teses sobre o ensino de química nos programas de pós-graduação em ensino de ciências e matemática - Área 46/Capes (2000-2008). Tese de doutorado em Química - Universidade Federal de São Carlos, São Carlos, 2011.

FRANCISCO, C. A.; ALEXANDRINO, D. M.; QUEIROZ, S. L. Análise de dissertações e teses sobre o ensino de química no Brasil: produção científica de programas de pós-graduação 
em destaque. Investigações em Ensino de Ciências, v. 20, n. 3, p. 21-60, 2015.

FRANCISCO JÚNIOR, W. E. Estratégias de leitura na educação química e na formação docente: necessidades e contribuições de um planejamento crítico. Tese de doutorado em Química - Universidade Estadual Paulista "Júlio de Mesquita Filho", Araraquara, 2011.

GIBIN, G. B. Atividades experimentais investigativas como contribuição ao desenvolvimento de modelos mentais de conceitos químicos. Tese de doutorado em Ciências - Universidade Federal de São Carlos, São Carlos, 2013.

GONÇALVES, F. P. A problematização das atividades experimentais no desenvolvimento profissional e na docência dos formadores de professores de química. Dissertação de mestrado em Educação Científica e Tecnológica - Universidade Federal de Santa Catarina, Florianópolis, 2009.

GONÇALVES, F. P. O texto de experimentação na educação em química: discursos pedagógicos e epistemológicos. Dissertação de mestrado em Educação Científica e Tecnológica - Universidade Federal de Santa Catarina, Florianópolis, 2005.

GONÇALVES, F. P.; MARQUES. C. A. Contribuições pedagógicas e epistemológicas em textos de experimentação no ensino de química. Investigações em Ensino de Ciências, v. 11, n. 2, p. 219-238, 2006.

GONÇALVES, F. P.; MARQUES. C. A. A problematização das atividades experimentais na educação superior em química: uma pesquisa com produções textuais docentes. Química Nova, v. 34, n. 5, p. 899-904, 2011.

GONÇALVES, F. P.; MARQUES. C. A. A problematização das atividades experimentais na educação superior em química: uma pesquisa com produções textuais docentes - parte II. Química Nova, v. 35, n. 4, 837-843, 2012a.

GONÇALVES, F. P.; MARQUES. C. A. A circulação inter e intracoletiva de pesquisa e publicações acerca da experimentação no ensino de química. Revista Brasileira de Pesquisa em Educação em Ciências, v. 12, n. 1, p. 181-204, 2012b.

KIOURANIS, N. M. M. Experimentos mentais no ensino de ciências: implementação de uma sequência didática. Tese de doutorado em Ensino de Ciências - Universidade Estadual Paulista "Júlio de Mesquita Filho", Bauru, 2009.

MALDANER, O. A. A formação inicial e continuada de professores de química: professor/pesquisador. 4. ed. Ijuí: Unijuí, 2013.

MEGID NETO, J. Tendências da pesquisa acadêmica sobre o ensino de ciências no nível fundamental. Tese de doutorado em Educação - Universidade Estadual de Campinas, Campinas, 1999.

MELO, M. R. Elaboração e análise de uma metodologia de ensino voltada para as questões sócio-ambientais na formação de professores de química. Tese de doutorado em Educação Universidade de São Paulo, São Paulo, 2010.

MILARÉ, T. A pesquisa em ensino de química na universidade de São Paulo: estudo das dissertações e teses (2006 a 2009) sob a perspectiva fleckiana. Tese de doutorado em Ensino de Ciências - Universidade de São Paulo, São Paulo, 2013. 
MILARÉ, T.; REZENDE, D. B. A pesquisa em ensino de química nos diferentes programas de pós-graduação da Universidade de São Paulo. In: ENCONTRO NACIONAL DE ENSINO DE QUÍMICA, 15., 2010, Brasília. Anais... Brasília, 2010. Ref. 622-1.

MOREIRA, M. A. A área de ensino de ciências e matemática na CAPES: em busca de qualidade e identidade. In: NARDI, R. (Org.). A pesquisa em ensino de ciências no Brasil: alguns recortes. São Paulo: Escrituras, 2007, p. 19-49.

MORI, R. C.; CURVELO, A. A. S. Química no ensino de ciências para as séries iniciais: uma análise de livros didáticos. Ciências \& Educação, v. 20, n. 1, p. 243-258, 2014.

NEVES, M. L. R. C. O interesse de estudantes do ensino fundamental de uma escola pública por atividades de ensino de ciências: um estudo transversal e longitudinal. Tese de doutorado em Educação - Universidade Federal de Minas Gerais, Belo Horizonte, 2010.

OLIVEIRA, N. Atividades de experimentação investigativas lúdicas no ensino de química: um estudo de caso. Tese de doutorado em Química - Universidade Federal de Goiás, Goiânia, 2009.

ORNELLAS, J. F. Interação verbal e atividade prática experimental investigativa: dimensões para repensar a formação inicial de professores de química. Dissertação de mestrado em Educação - Universidade Estadual Paulista "Júlio de Mesquita Filho", Presidente Prudente, 2012.

PHILIPPSEN, E. A. Química, ambiente e atmosfera: estratégias para formação docente em química. Dissertação de mestrado em Ensino de Ciências - Universidade de Brasília, Brasília, 2012.

POPPOLINO, G. G. Utilizando a abordagem histórica com experimentação para trabalhar conceitos de química no ensino médio. Dissertação de mestrado em Ensino de Ciências e Matemática - Centro Federal de Educação Tecnológica Celso Suckow da Fonseca, Rio de Janeiro, 2013.

RUSSO, A. A. Proposta curricular do estado de Minas Gerais: uma análise pela ótica de professores e alunos do ensino médio. Dissertação de mestrado profissional em Química Universidade Federal de São Carlos, São Carlos, 2013.

SANTOS, E. D. A experimentação no ensino de ciências de $5^{a}$ a $8^{a}$ séries do ensino fundamental: tendências da pesquisa acadêmica entre 1972 e 1995. Dissertação de mestrado em Educação - Universidade Estadual de Campinas, Campinas, 2001.

SANTOS, W. G. Química no ensino médio: o papel das experimentações na promoção da aprendizagem significativa química no ensino médio: o papel das experimentações na promoção da aprendizagem significativa. Dissertação de mestrado em Ensino das Ciências Universidade do Grande Rio, Rio de Janeiro, 2012.

SCHNETZLER, R. P. A pesquisa em ensino de química no Brasil: conquistas e perspectivas. Química Nova, v. 25, n. 1, p. 14 - 24, 2002.

SILVA. A. C. T. Estratégias enunciativas em salas de aula de química: contrastando professores de estilos diferentes. Tese de doutorado em Educação - Universidade Federal de Minas Gerais, Belo Horizonte, 2008.

SILVA, E. E. O ambiente como contexto para o ensino das transformações químicas. 
Dissertação de mestrado profissional em Química - Universidade Federal de São Carlos, São Carlos, 2011.

SILVA, P. D. S. O projeto temático na sala de aula: mudanças nas interações discursivas. Tese de doutorado em Educação - Universidade Federal de Minas Gerais, Belo Horizonte, 2009.

SILVA, M. Um estudo de aspectos do sistema solo planta a partir de uma abordagem investigativa no ensino de química. Dissertação de mestrado profissional em Química Universidade Federal de São Carlos, São Carlos, 2012.

SILVA JÚNIOR, C. N. A energia e suas implicações no ensino-aprendizagem da química. Tese de doutorado em Química - Universidade Federal do Rio Grande do Norte, Natal, 2010.

SILVA, R. T.; CURSINO, A. C. T.; AIRES, J. A.; GUIMARÃES, O. M. Contextualização e experimentação uma análise dos artigos publicados na seção "experimentação no ensino de química" da revista Química Nova na Escola 2000-2008. Ensaio: Pesquisa em Educação em Ciências, v. 11, n. 2, p. 277-298, 2009.

SILVA, R. R. GAUCHE, R.; BAPTISTA, J. A.; SANTOS, W. L. P.; MÓL, G. S.; MACHADO, P. F. L. Laboratório de pesquisas em ensino de química da Universidade de Brasília LPEQ/UnB: concepções, relatos e reflexões. Revista Virtual de Química, v. 3, n. 1, p. 14-26, 2011.

SILVA, J. F. J.; CURI, E.; SCHIMIGUEL, J. Um cenário sobre a pesquisa em educação estatística no boletim de educação matemática - Bolema, de 2006 até 2015. Bolema, v. 31, n. 58, p. 679-698, 2017.

SILVA, O. B.; QUEIROZ, S. L. Mapeamento da pesquisa no campo da formação de professores de química no Brasil. Investigações em Ensino de Ciências, v. 21, n. 1, p. 62-93, 2016.

SILVA, O. B.; QUEIROZ, S. L. Produção acadêmica sobre a formação de professores de química no Brasil: focos temáticos das dissertações e teses defendidas no período de 2001 a 2010. Alexandria: Revista de Educação em Ciência e Tecnologia, v. 10, n. 1, p. 271-304, 2017.

SITHOLE, G. Z. S. Resgate dos materiais e das culturas locais para o ensino na química. Tese de doutorado em Educação - Pontifícia Universidade Católica de São Paulo, São Paulo, 2004.

SOUZA, D. D. D. Multimodalidade na construção do conhecimento em sala de aula de química: caracterizando a evolução na aprendizagem. Tese de doutorado em Educação Universidade de São Paulo, São Paulo, 2013.

SOUZA, K. A. F. D. Estratégias de comunicação em química como índices epistemológicos: análise semiótica das ilustrações presentes em livros didáticos ao longo do século XX. Tese de doutorado em Química - Universidade de São Paulo, São Paulo, 2012.

SOUZA, A. C.; BROIETTI, F. C. D. Atividades experimentais: uma análise de artigos da Revista Química Nova na Escola. In: ENCONTRO NACIONAL DE PESQUISA EM EDUCAÇÃO EM CIÊNCIAS, 11., 2017, Florianópolis. Anais... Florianópolis, 2017.

SUART, R. C. Habilidades cognitivas manifestadas por alunos do ensino médio de química 
em atividades experimentais investigativas. Dissertação de mestrado em Ensino de Ciências Universidade de São Paulo, São Paulo, 2008.

TERCI, D. B. L. Aplicações analíticas e didáticas de antocianinas extraídas de frutas. Tese de doutorado em Química Analítica - Universidade Estadual de Campinas, Campinas, 2004.

TEIXEIRA, P. M. M. Pesquisa em ensino de biologia no Brasil: um estudo baseado em dissertações e teses. Tese de doutorado em Educação - Universidade Estadual de Campinas, Campinas, 2008.

TEIXEIRA, P. P. M.; MEGID NETO, J. Investigando a pesquisa educacional. Um estudo enfocando dissertações e teses sobre ensino de biologia no Brasil. Investigações em Ensino de Ciências, v. 11, n. 2, p. 261-282, 2006.

ZANDONAI, D. P. A inserção da química verde no curso de licenciatura em química do $D Q-$ UFSCar: um estudo de caso. Dissertação de mestrado profissional em Química Universidade Federal de São Carlos, São Carlos, 2013.

WALVY, O. W. C. Construindo saber docente interdisciplinar: a termogravimetria em um laboratório didático. Tese de doutorado em Educação - Universidade Federal Fluminense, Niterói, 2008.

\section{SOBRE AS AUTORAS}

RENATA FARIA DE SOUZA. Licenciada em Ciências pela Universidade Luterana do Brasil, mestra em Química pela Universidade Federal de Uberlândia e doutora em Ciências pela USP. Atua como professora no colégio Zênite, em Itumbiara, Goiás.

PATRÍCIA FERNANDA DE OLIVEIRA CABRAL. Licenciada em Química pela Universidade Federal de Alfenas, mestra em Ciências pela USP e doutoranda em Educação em Ciências pelo Programa de Pós-Graduação Interunidades em Ensino de Ciências da USP.

SALETE LINHARES QUEIROZ. Bacharel em Química Industrial pela Universidade Federal do Ceará, mestra em Química pela Universidade Federal de São Carlos e doutora em Química pela Universidade Estadual "Júlio de Mesquita Filho". Atua como professora no Instituto de Química de São Carlos da USP e como diretora do Centro de Divulgação Científica e Cultural da mesma Universidade. É bolsista de produtividade em pesquisa do CNPq e editora da revista Química Nova na Escola.

Recebido: 01 de julho de 2018.

Revisado: 28 de outubro de 2018.

Aceito: 21 de dezembro de 2018. 